\title{
PROBLEMS OF THE SUPPLY CHAIN RELIABILITY EVALUATION
}

\author{
Valery Lukinskiy ${ }^{1}$, Vladislav Lukinskiy ${ }^{2}$, Rostislav Churilov ${ }^{3}$ \\ ${ }^{I}$ National Research University Higher School of Economics \\ Phone:007(812)7466623.E-mail: lukinskiy@mail.ru \\ ${ }^{2}$ Saint- Petersburg University Graduate School of Management \\ Phone:007(812)3293234.E-mail: vladas27@mail.ru \\ ${ }^{3}$ Saint-Petersburg State University of Economics \\ Phone: 007(812)7660117. E-mail: rostbeatl@gmail.com
}

\begin{abstract}
Reliability is one of the most important characteristics of the functioning of supply chains. The carried out analysis have shown that, despite some progress, a number of questions remain open, in particular, the terminology, the selection of key indicators and methods of their calculation as well as there is no economic evaluation of redundant and restorable supply chains.

The paper presents a formed conceptual apparatus of logistics systems' reliability theory, the discrete-continuous model of the simple supply chain's functioning as well as it contains the proposal to assess the reliability not only with the help of faultlessness but as well by using the leading function of costs associated with the maintenance of supply chains' operability.
\end{abstract}

Keywords: reliability, supply chains, terminology, methods of analysis, models of failures

\section{Introduction}

Reliability is one of the most important characteristics of the functioning of supply chains since it has a significant impact on the completeness and quality of delivered parties, on the execution time of logistics cycle and on logistics costs in supply chains. Since the processes of interaction between the companies, that are participants of the supply chain, become more complicated, this leads to the need of improvement of methods used to assess the reliability of supply chains and to search for active ways to improve reliability.

Analysis of a number of studies have shown that in many matters relating to the reliability of supply chains (such as terminology, classification of concepts and principles, analytical tools, failure models and its experimental evaluation) there is a significant range of opinions. Let us consider them in detail and in our opinion it will help to form the topics of research aimed at solving problems of reliability assessment of supply chains.

First of all, start with the terminology. According to (Institute of Electrical and Electronics Engineers, 1990) "reliability is defined as the ability of a system or component to perform its required functions under stated conditions for a specified period of time". Obviously, this definition refers to technical systems; however it is used for risk assessment in supply chains (Wolfgang \& Thorsten, 2006). In study (Blanchard, 2004) there is a similar definition: "Reliability can be simply defined as the probability that a system or a product will perform in a satisfactory manner for a given period of time when used under specified operating conditions".

Another approach to the interpretation of reliability is given in (Mirotin \& Sergeev, 2002; Zaitzev \& Bochazev, 2010; Zaitzev \& Uvarov, 2012). For instance, study (Mirotin \& Sergeev, 2002) contains the term "economic reliability". The economic reliability is defined as "the system's feature, which allows ensuring the values of guaranteed economic indicators of the system with minimal costs (material, labour, etc.) or with the greatest possible economic benefit in a planned period of time".

Even greater diversity occurs when using terms such as "disruption", "interruption", etc. Obviously, without the systematisation of basic concepts it is difficult to solve the problem of reliability assessment of supply chains.

Secondly, consider the analytical tools. For our purpose the studies, that contain the quantitative methods of assessing the reliability of supply chains, can be divided into two groups. 
In the first group of studies the assessment of the reliability of supply chains is carried out on the basis of the so-called circuit reliability (serial, parallel and mixed compound of elements with different types of redundancy - "active/hot", "standby/cold") (Blanchard, 2004; Mirotin \& Sergeev, 2002; Zaitzev \& Bochazev, 2010). All estimates are based on the probability of faultless operation of the elements of chain.

The second group of studies contains failure models, which, by analogy with technical systems (Gertsbakh \& Kordonsky, 1966), can be presented by the following types:

- the model of the "perfect" or "ideal" order (Ballou, 1999; Christopher, 2004);

- the model of "supply and demand" (Wolfgang \& Thorsten, 2006);

- the "just-in-time" model (Lukinskiy \& etc., 2007).

Common to these groups is that they are based on probability theory. According to (Blanchard, 2004) probability, the first element in the reliability definition, is usually stated as a quantitative expression representing a fraction or a percent signifying the number of times that an event occurs (successes), divided by the total number of trails.

In general, by characterizing this direction it should be emphasized that, on the one hand, qualitative indicators and expert evaluations of reliability were replaced by quantitative indicators of assessment and, on the other hand, most models require further development and generalization.

Thirdly, consider experimental evaluation methods. In most studies the assessment of reliability indicators in supply chains reduces itself to recording the amount of " $n$ " disruptions (interruptions) that occurred during the execution of $\mathrm{N}$ logistics operations:

$S L=\frac{N-n}{N}=1-\frac{n}{N}$,

where $S L$ - service level. operation $\mathrm{P}$

The level of service, which is calculated by the formula 1, is taken as the probability of faultless

However, the uncertainty of this approach becomes apparent if not one but several features, which characterize the state of disruption (interruption), are recorded during the execution of a logistics operation.

For example, Table 1 shows the results of calculation of faultlessness for several options of perfect order's formation in case of 20 deliveries and three criteria of failures as well as various combinations of these criteria (Zaitzev \& Uvarov, 2012).

Table 1. The calculation results of probability of faultless formation of perfect order

\begin{tabular}{|c|c|c|c|c|c|c|c|c|}
\hline \multirow{2}{*}{ Criterion of failure } & \multirow{2}{*}{$\begin{array}{c}\begin{array}{c}\text { Base } \\
\text { option }\end{array} \\
P_{i}^{*}\end{array}$} & \multirow{2}{*}{$\begin{array}{c}\begin{array}{c}\text { First } \\
\text { option }\end{array} \\
n_{i}^{* *}\end{array}$} & \multicolumn{3}{|c|}{ Second option } & \multicolumn{3}{|c|}{ Third option } \\
\hline & & & (3) & (2) & (1) & (3) & (2) & (1) \\
\hline 1. Fulfillment of an order out-of-time & 0,9 & 2 & 2 & - & - & 1 & - & 1 \\
\hline $\begin{array}{l}\text { 2. Number of orders that are fulfilled not to } \\
\text { the fullest extent }\end{array}$ & 0,8 & 4 & $(2)$ & 2 & - & (1) & 2 & 1 \\
\hline $\begin{array}{l}\text { 3. Number of improperly executed } \\
\text { documents }\end{array}$ & 0,5 & 10 & $(2)$ & $(2)$ & 6 & (1) & (2) & 7 \\
\hline Total number of all types of failures & & 16 & 2 & 2 & 6 & 1 & 2 & 9 \\
\hline $\begin{array}{l}\text { Probability of faultless formation of perfect } \\
\text { order }\end{array}$ & 0,36 & 0,2 & \multicolumn{3}{|l|}{0,5} & \multicolumn{3}{|l|}{0,4} \\
\hline
\end{tabular}

Let us analyse the results shown in Table 1. The base variant of calculating the probability of faultless formation of perfect order corresponds to the classical rule of serial connection of elements.

$P_{0}=\prod_{i=1}^{3} P_{i}=0,9 \times 0,8 \times 0,5=0,36$.

The first option presents independence and the lack of correlation of failures when executing each operation and the corresponding probability is determined by the formula 1 . 


$$
P_{1}=1-\frac{\Sigma n_{i}}{N}=0,2
$$

The second option includes the maximum possible combinations of events: three criteria of failures occurred simultaneously when executing two orders; two criteria of disruptions happened during execution of another two orders and only one criterion of failure occurred when executing last six orders, the corresponding probability is $P_{2}=0,5$.

The third option is one of the possible combinations of criteria of failures in a single delivery, the probability of faultless formation equals to $P_{3}=0.4$.

Thus, by analysing the different sources one can make the following conclusions:

1. Unified definitions of key terms as well as decomposing of supply chain into components are lacking when assessing the reliability of logistics systems.

2. Different studies lack a single opinion about supply chains, their properties and characteristics, which is why there are problems in description of supply chains and in analysis of the processes occurring in them.

3. Methods for assessing the reliability, which are proposed in considered studies, can be used only if initial data is available but methods for data collection are not considered.

4. The probability of faultless operation is considered as the main indicator of reliability, but there are no methods for reliability assessment that characterize restorability and operability.

5. It is proposed to base on the number of failures when assessing flows of failures, but there is no proper classification of failures and consideration of consequences of their occurrence in considered studies.

\section{Formation of Conceptual Apparatus of Logistics Systems' Reliability Theory}

Table 2 shows the basic terms and definitions that have been formed on the basis of an analysis of studies on logistics and supply chain management studies, as well as the following approaches:

1) technical approach based on the theory of reliability of complex systems;

2) economic approach that involves evaluation of the reliability of supply chains on the base of logistics costs, breaches of contractual obligations (fines, etc.) or KPI indicators;

3) situational approach that includes recording of time parameters of business processes in supply chains, which are based, in particular, on the fundamental concepts of JIT, QR, etc.

Table 2. The revised terms of supply chain's reliability theory

\begin{tabular}{|c|c|}
\hline Term & Definition \\
\hline Reliability & $\begin{array}{l}\text { It is property to maintain all characteristics of supply chain \& its links/elements within the established } \\
\text { values (faultlessness, durability, restorability, conservability), which characterize supply chain's } \\
\text { ability to perform all of its functions in the concrete conditions in accordance with the terms of } \\
\text { contracts between its parties }\end{array}$ \\
\hline Faultlessness & $\begin{array}{l}\text { Property that characterizes supply chain's ability to operate continuously without disruptions for a } \\
\text { specified time in accordance with the contractual terms between its parties }\end{array}$ \\
\hline Restorability & $\begin{array}{l}\text { It is property, which characterizes ability of supply chain to eliminate emergent disruptions and its } \\
\text { consequence, brining the chain back to operable good state }\end{array}$ \\
\hline Runability/ Good state & $\begin{array}{l}\text { The supply chain's state, in which its functioning corresponds to the terms of contracts concluded } \\
\text { between the members of this supply chain }\end{array}$ \\
\hline Fault/ faulty state & $\begin{array}{l}\text { The state of the supply chain at which it is able to perform all of its functions, in spite of the violation } \\
\text { of the terms of contracts between its parties }\end{array}$ \\
\hline Operability & $\begin{array}{l}\text { The state of the supply chain at which it is able to perform its functions in accordance with the } \\
\text { agreements between the parties in the supply chain }\end{array}$ \\
\hline Inoperability & $\begin{array}{l}\text { The state of the supply chain at which it is not able to perform its functions in accordance with the } \\
\text { agreements between the parties to the supply chain for any reason }\end{array}$ \\
\hline Defect & $\begin{array}{l}\text { Internal action entailing acceptable deviation from the terms of contracts between supply chain } \\
\text { parties }\end{array}$ \\
\hline Damage & $\begin{array}{l}\text { External action entailing acceptable deviation from the terms of contracts between supply chain } \\
\text { parties }\end{array}$ \\
\hline Failure/ Disruption & $\begin{array}{l}\text { Loss of supply chain's or its elements the ability to perform its functions in accordance with the } \\
\text { contracts between chain's members }\end{array}$ \\
\hline $\begin{array}{l}\text { Interruption/ transient } \\
\text { fault }\end{array}$ & $\begin{array}{l}\text { Failure/ Disruption, which leads to a short-term loss of operability \& could be removed by negligible } \\
\text { efforts without significant investment of time and finances }\end{array}$ \\
\hline
\end{tabular}


In our opinion the formation of the conceptual apparatus has to include not only revised terms and definitions but failure modes that occur in the supply chain (Table 3) and the classification of supply chains (Table 4).

Undoubtedly, Table 3 covers a small part of failures that occur in real supply chains. Therefore, in our view, provided information is the first step in this direction and, of course, research should be continued.

A similar conclusion can be drawn and for Table 4, which presents consolidated classification of supply chains in terms of reliability. In the future the Table 4 should be extended by including the types of redundancy of elements ("hot", "cold"), the presence of "switches" (here the case is about participation of the operator in the supply chain management), etc.

Thus, supply chains are complex systems, which have independent functionality, they consist of many interacting components (subsystems) and thereby they acquire new properties that cannot be reduced to the properties of subsystem level.

Table 3. Failure modes that occur in the supply chain

\begin{tabular}{|c|l|l|}
\hline Group of failures & Description & Example \\
\hline $\begin{array}{c}\text { Failures in } \\
\text { quantity }\end{array}$ & $\begin{array}{l}\text { The deviation of the actual quantity of goods in the supply from } \\
\text { planned }\end{array}$ & Shortage, overload, etc. \\
\hline $\begin{array}{c}\text { Failures in quality } \\
\text { Inconsistency of the actual quality of goods agreed in the order }\end{array}$ & $\begin{array}{l}\text { Wetting of cargo, cargo damage, } \\
\text { etc. }\end{array}$ \\
\hline $\begin{array}{c}\text { Failures in } \\
\text { nomenclature }\end{array}$ & Inconsistency of the actual delivery of the ordered nomenclature & $\begin{array}{l}\text { Incorrect complete set unit load, } \\
\text { etc. }\end{array}$ \\
\hline $\begin{array}{c}\text { Failures in the } \\
\text { document }\end{array}$ & $\begin{array}{l}\text { Incorrect execution of documents or errors in their of treatment } \\
\text { between SC members }\end{array}$ & $\begin{array}{l}\text { Loss or error in compiling of } \\
\text { documents, etc. }\end{array}$ \\
\hline $\begin{array}{c}\text { Failures in the } \\
\text { informing }\end{array}$ & $\begin{array}{l}\text { Errors in the process of exchange of information between SC } \\
\text { members }\end{array}$ & $\begin{array}{l}\text { Late informing about the arrival } \\
\text { of transport for loading, etc. }\end{array}$ \\
\hline $\begin{array}{c}\text { Temporary } \\
\text { failures }\end{array}$ & Disruption of a schedule of operations in the SC & $\begin{array}{l}\text { Delay loading or late arrival of } \\
\text { the vehicle, etc. }\end{array}$ \\
\hline $\begin{array}{c}\text { Equipment failure } \\
\text { Emergency } \\
\text { situations }\end{array}$ & $\begin{array}{l}\text { Failures of technical equipment used in the supply chain } \\
\text { majeure and other causes, which may not affect members of the } \\
\text { supply chain }\end{array}$ & $\begin{array}{l}\text { Breakage the vehicle, material } \\
\text { handling equipment, etc. }\end{array}$ \\
\hline
\end{tabular}

Table 4. Classification of supply chains

\begin{tabular}{|c|c|l|}
\hline Criterion & Types & Example \\
\hline \multirow{2}{*}{$\begin{array}{c}\text { By the number of planned } \\
\text { realizations }\end{array}$} & One-time & For single use only \\
\cline { 2 - 3 } & Reusable & For continuous operation \\
\hline $\begin{array}{c}\text { Where possible eliminate } \\
\text { failures and their } \\
\text { consequences }\end{array}$ & Restorable & $\begin{array}{l}\text { Part of the failures occurred and their consequences can be eliminated, } \\
\text { and the chain is restored }\end{array}$ \\
\cline { 2 - 3 } & Not restorable & Disruption of supply is due to any failure in the supply chain \\
\hline $\begin{array}{c}\text { By the presence of } \\
\text { duplicate (parallel) } \\
\text { elements }\end{array}$ & Redundant & There are in the chain parallel duplicate elements \\
\cline { 2 - 3 } & Nonredundant & All elements and links in the chain have a serial connection \\
\hline
\end{tabular}

Obviously, in the supply chain one should allocate links of chain (participants of the supply chain) and elements (operations that are performed in the chain). Such decomposing, which allows presenting a particular supply chain as a complex of companies and the operations they perform, enables the assessment of any supply chain.

For calculation of the reliability indicators of logistics system let's use the idea of a simple supply chain (SSC). By "simple supply chain" we shall mean the following:

- a part of the logistics chain (channel), which include at least two major links of logistics system such as "supplier" and "consumer" that are connected to each other by logistics operations: purchase, order processing, transportation and storage, etc.;

- SSC extension is possible due to main intermediaries ("the third party" in logistics): carriers, freight forwarders, warehouses, etc.;

- any supply chain can be represented as a set of individual SSC. 
The proposed decomposing is simple and has adjustable level of detail that provides the best way to analyse the functioning of the supply chain.

We should also note the additional properties of supply chains and, first of all, the property of selforganization, which is purposeful adaptive behaviour in complex environments through adequate changes both internal and external conditions. Essentially supply chains are considered restorable, which is why when assessing reliability one should take into account this the most important property.

Assessing the impact of such characteristics of supply chains as longevity and storage-ability on reliability is complicated, as they are more dependent on external factors, which are characterized by a high degree of uncertainty. Certainly the consideration of such characteristics can improve the accuracy of reliability assessment, but at this stage they can be neglected.

\section{Development of Discrete-Continuous Model of the Simple Supply Chain}

In accordance with described approach the supply chain can be presented as a discrete-continuous model and described as a graph, which is based on the Gantt chart:

- the order quantity, its nomenclature, product quality, availability of properly executed documents, etc. can be referred to discrete variates;

- time characteristics and characteristics of reliability of technical products used in the supply chain can be referred to continuous variates;

- discrete-continuous or combined variates can be introduced for registration of expenditures of time that is required to perform operations until binary indicator "fulfilment of schedule", which will take the values "yes" or "no".

Suppose that we have the supply chain in which the delivery of finished goods is made from the plant of manufacturer to warehouse or distribution centre (Figure 1). The graph illustrates that the chain includes 8 basic operations that must be made to fulfil the order within the specified time intervals:

1. Agreement of supply $\left[0 ; \mathrm{t}_{1}\right]$.

2. Order packing at warehouse $\left[\mathrm{t}_{1} ; \mathrm{t}_{2}\right]$.

3. Processing of documents for cargo dispatch $\left[\mathrm{t}_{2} ; \mathrm{t}_{3}\right]$.

4. Vehicle loading $\left[t_{3} ; t_{4}\right]$.

5. Cargo transportation $\left[\mathrm{t}_{4} ; \mathrm{t}_{5}\right]$.

6. Unloading $\left[\mathrm{t}_{5} ; \mathrm{t}_{6}\right]$.

7. Processing of documents when receiving cargo $\left[\mathrm{t}_{6} ; \mathrm{t}_{7}\right]$.

8. Placing of cargo at warehouse $\left[\mathrm{t}_{7} ; \mathrm{t}_{8}\right]$.

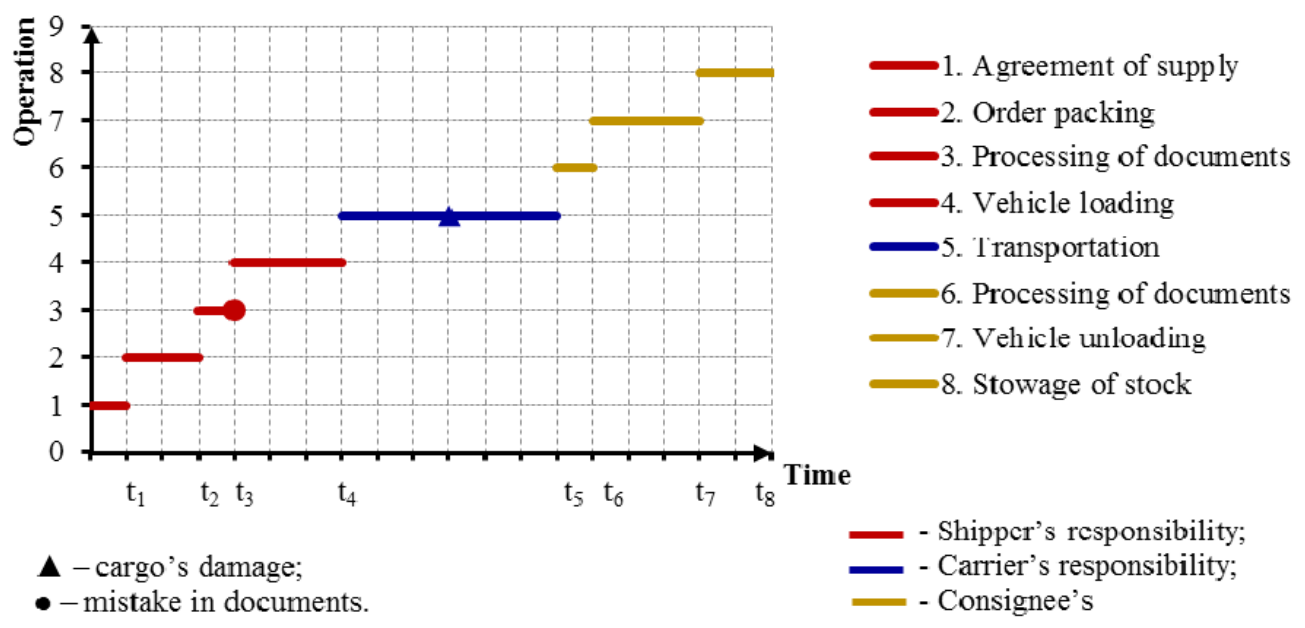

Figure 1. The supply chain can be represented as a graph based on the principle of a Gantt chart

Proposed graph shows the time characteristics of operations as well as allows illustrating possible parallel execution of these operations, for instance, processing of documents and vehicle loading. Failures (disruptions) in the supply chain can be marked on the chart. For example, mistake in documents and cargo damage occurred during transportation are marked by appropriate symbols on Figure 1.

Consider the example of the formation of costs flow in the supply chain (Figure 2). Assume that during the first delivery the vehicle was loaded with a delay that is why the carrier invoiced penalty for waiting time on 5000 roub. (see the $1^{\text {st }}$ delivery on Figure 2). 


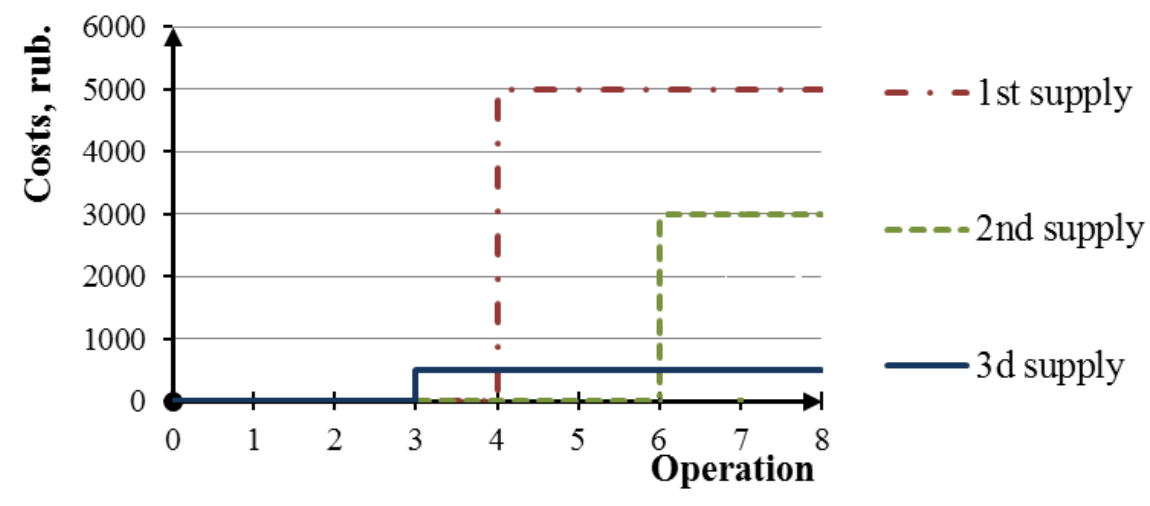

Figure 2. The diagram of formation of flow of costs associated with the maintenance of supply chains' operability

During fulfilling of the second delivery when unloading the vehicle at warehouse the cargo of consignee was damaged and the damage amounted to 3000 roubles (see the $2^{\text {nd }}$ delivery on Figure 2). During the third delivery of cargo the transport documents were incorrectly processed, the correction of which costs 500 roubles (see the $3^{\text {rd }}$ delivery).

When forming a discrete-continuous model it is necessary to take into account that the number of operations may different depending on the complexity of the supply chain, as well as the allocation of responsibility between participants, for instance, the carrier is responsible for transportation, etc.

\section{Evaluating the Reliability of Logistics Operations on the Basis of Statistical Data}

According to the developed model, reliability is assessed on the basis of the collected data on execution of operations for several deliveries in the supply chain. First of all, the assessment of operations is made, after that the whole supply chain is evaluated. When estimating operations it is necessary to distinguish between failure modes, since they have different effects on the functioning of the supply chain and entail different consequences. For example, operations that involve equipment, namely, vehicles (transportation), cranes, forklifts, conveyors (loading, unloading, materials handling), are characterized by means of intensity (Figure 3) or the leading function of flow of failures and corresponding indicators of reliability: mean-time-between-failures, availability factor, etc.

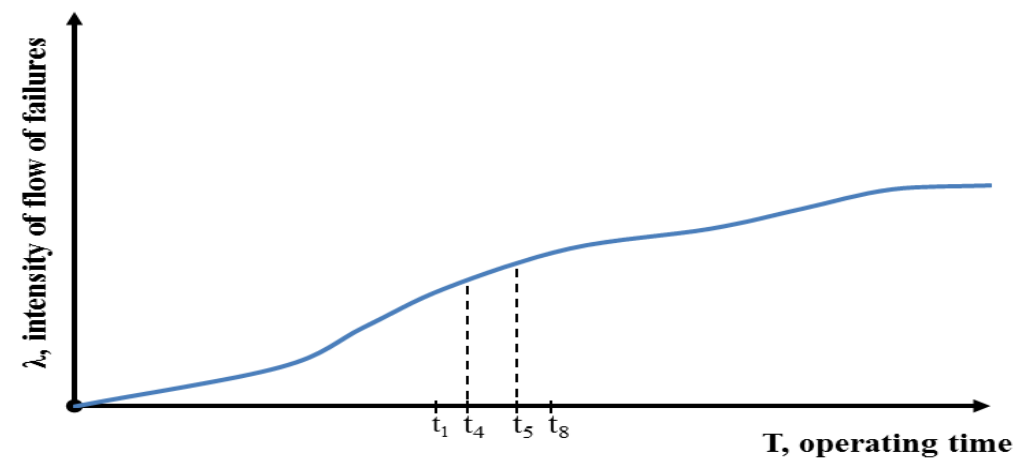

Figure 3. Intensity of flow of failures of vehicle

The studies have shown that it is necessary to distinguish three main indicators of reliability of the supply chain: faultlessness, restorability and the costs of maintenance of operability. The first two indicators can be described with the help of probabilistic characteristics of execution of operations in supply chain and these characteristics can be calculated by the combination of different methods depending on different failure modes. The costs of maintenance of the supply chain's operability should be calculated quantitatively depending on the frequency of their occurrence. Thus, the assessment of the reliability of the supply chain should be carried out on the basis of the combination of probability and cost characteristics of operations.

As pointed out above, in many studies the probability of faultless operation of the supply chain is used as the main indicator. Obviously that for a discrete-continuous model with a serial connection of elements the formula for serial connection of elements can be used for calculating faultlessness. 
Besides, there is a certain probability that the failure will occur, but its effects can be eliminated, leaving the supply chain in good operation condition.

To take into account the restoration of the supply chain, for example, with the help of redundant elements after the failure when the $i^{\text {th }}$ operation is executed, the values of $\mathrm{P}_{\mathrm{i}}$ should be corrected.

Consider one of the possible approaches based on addition theorem and multiplication theorem of the probability of events.

Assume that event $\mathrm{A}$ is the formation of a perfect order and its probability is $\mathrm{p}_{\mathrm{A}}$, and thus the probability of imperfect order equals to $\mathrm{q}_{\mathrm{A}}=1-\mathrm{p}_{\mathrm{A}}$.

In warehouses of supply chain, which receive orders (or where they are formed), there are insurance stocks. Then the event $B$ is the availability of safety stock and its probability is $p_{B}$, and the probability of its absence (i.e. deficit) equals to $\mathrm{q}_{\mathrm{B}}=1-\mathrm{p}_{\mathrm{B}}$.

The calculation formula based on the theorem about the repetition of experiments to assess the probability of a combination of events $\mathrm{A}$ and $\mathrm{B}$ can be written as:

$\mathrm{Q}+\mathrm{P}=\mathrm{p}_{\mathrm{A}} \mathrm{p}_{\mathrm{B}}+\mathrm{p}_{\mathrm{A}} \cdot \mathrm{q}_{\mathrm{B}}+\mathrm{p}_{\mathrm{B}} \cdot \mathrm{q}_{\mathrm{A}}+\mathrm{q}_{\mathrm{A}} \cdot \mathrm{q}_{\mathrm{B}}$

Obviously, the sum of the first three summands reflects the probability of faultless performance of considered logistics operation - $\mathrm{p}$, and the last summand reflects the probability of failure $-\mathrm{q}$.

Further development of this approach, which reflects the specifics of the internal redundancy of the supply chain, should provide not only more accurate probable description of the perfect order but also the quantitative status of safety stock at the time of delivery (or formation).

Finally, if we assume that all failures and corrective actions lead to costs, the reliability evaluation reduces to the calculation of these costs, i.e. the flows of failures in supply chains can be presented as the flow of costs of operability's maintenance. Then on the analogy with technical systems one can consider the intensity of flow of costs per delivery as well as an integral characteristic, namely the leading function of flow of costs per delivery.

\section{Approbation: the Example of Calculating the Reliability of the Supply Chain}

To illustrate the developed approach let's consider the simulation results of ten deliveries of products from producer to consumer without intermediaries taking into account that any delivery can be presented as the combination of eight logistics operations (Table 5). Accordingly, the first three deliveries are shown on Figure 2.

Apart from failures the Table 5 shows the costs associated with the restoration of supply chain's operability.

Table 5. Recording of failures (disruptions) and costs associated with the maintenance of supply chains' operability

\begin{tabular}{|c|c|c|c|c|c|c|c|c|}
\hline \multirow{2}{*}{ № of supply } & \multicolumn{7}{|c|}{ Costs that are incurred during execution of operations in supply chain, rubles } \\
\cline { 2 - 9 } & $\mathbf{1}^{\text {st }} \mathbf{o p .}$ & $\mathbf{2}^{\text {nd }} \mathbf{o p .}$ & $\mathbf{3}^{\text {rd }} \mathbf{o p .}$ & $\mathbf{4}^{\text {th }} \mathbf{o p}$. & $\mathbf{5}^{\text {th }} \mathbf{o p .}$ & $\mathbf{6}^{\text {th }} \mathbf{o p .}$ & $\mathbf{7}^{\text {th }} \mathbf{o p .}$ & $\mathbf{8}^{\text {th }} \mathbf{o p .}$ \\
\hline 1 & 0 & 0 & 0 & 5000 & 0 & 0 & 0 & 0 \\
\hline 2 & 0 & 0 & 0 & 0 & 0 & 3000 & 0 & 0 \\
\hline 3 & 0 & 0 & 500 & 0 & 0 & 0 & 0 & 0 \\
\hline 4 & 0 & 0 & 0 & 0 & 0 & 0 & 0 & 0 \\
\hline 5 & 0 & 0 & 0 & 8000 & 0 & 0 & 1000 & 0 \\
\hline 6 & 0 & 0 & 0 & 0 & 0 & 0 & 0 & 0 \\
\hline 7 & 0 & 0 & 1000 & 0 & 0 & 0 & 0 & 0 \\
\hline 8 & 0 & 0 & 0 & 0 & 0 & 2000 & 0 & 0 \\
\hline 9 & 0 & 0 & 0 & 0 & 20000 & 0 & 0 & 0 \\
\hline 10 & 0 & 0 & 0 & 0 & 0 & 2000 & 0 & 0 \\
\hline Number of failures & 0 & 0 & 2 & 2 & 1 & 3 & 1 & 0 \\
\hline Total costs, y.e. & 0 & 0 & 1500 & 13000 & 20000 & 7000 & 1000 & 0 \\
\hline
\end{tabular}



(Table 6)

By using the data from the Table 5 let's calculate the indicators of reliability of the supply chain

Consider the approach to assessing the probability of faultless operation $\mathrm{P}_{0}$ without redundancy.

Since the supply chain consists of eight operations, which are performed sequentially, for calculation of $\mathrm{P}_{0}$ can be used the classical formula of probability theory:

$$
P_{0}=\prod_{i=1}^{8} P_{i}=1 \times 1 \times 0,8 \times 0,8 \times 0,9 \times 0,7 \times 0,9 \times 1=0,363,
$$

where $P_{i}-$ the evaluation of faultlessness of $i^{\text {th }}$ operation.

Value $P_{0}=0,366$ indicates that the supply chain is almost inoperable and requires adjustment.

Consider the approach to assessing the probability of faultless operation with account of redundancy when the 3,5 and 7 operations are executed.

We remind that operations 3 and 7 "processing of documents" include an assessment of the perfect order. Let's carry out calculations in several stages.

Operation 3. We assume that insurance stocks at the warehouse of producer were increased and it allows providing the probability of availability of stocks at level $\mathrm{P}_{\mathrm{ss}, 3}=0,7$. Then by formula 3 (assuming that the probability of faultlessness of the perfect order is $\mathrm{P}_{3}=0.8$ ) we find:

- the probability of formation of the perfect order ( $3^{\text {rd }}$ operation) equals to

$$
\begin{aligned}
\mathrm{P}_{3}^{*}= & 0,8 \cdot 0,7+0,8 \cdot 0,3+0,7 \cdot 0,2=0,94 ; \\
& \text { - the probability of failure } Q_{3}^{*}=0,06 .
\end{aligned}
$$

Operation 5. Let's assume that the insurance stock at the warehouse of producer provides the probability of faultless operation at level $\mathrm{P}_{\mathrm{ss}, 5}=0,8$. We believe that this stock is enough to ensure the operability of the chain in case of late delivery (probability of delay in the delivery $\mathrm{q}_{5}=0,1$ ). When using the formula 2, we obtain:

- the probability of faultlessness of $5^{\text {th }}$ operation equals to $\mathrm{P}_{5}{ }^{*}=0,98$;

- the probability of failure is $\mathrm{Q}_{5}{ }^{*}=0,02$.

Operation 7. During calculation we will try to take into account the relationship of operations in the supply chain. So taking into account corrected $3^{\text {rd }}$ operation, the option of the perfect order has the probability $\mathrm{P}_{3}{ }^{*}=0,94$.

However, after such operations as loading, transportation, unloading as well as because of possible natural loss, destruction of unit packages, theft, etc. we can assume that the value of $\mathrm{P}_{3}{ }^{*}$ will decrease, for example, to $\mathrm{P}_{3}{ }^{*}=0,84$. Provided that the amount of safety stock at the warehouse is sufficient (and remains at $\mathrm{P}_{7 . \mathrm{saf}}=0,8$ ), similar to the calculations at previous stages we obtain:

$\mathrm{P}_{7}^{*}=0,968 ; \mathrm{q}_{7}{ }^{*}=0,032$

\begin{tabular}{|c|c|c|c|c|c|c|c|c|c|}
\hline \multirow{2}{*}{ Indicator } & \multicolumn{8}{|c|}{ Logistics operations } & \multirow{2}{*}{ Comment } \\
\hline & 1 & 2 & 3 & 4 & 5 & 6 & 7 & 8 & \\
\hline Probability $\mathrm{P}_{\mathrm{i}}$ & 1,0 & 1,0 & 0,8 & 0,8 & 0,9 & 0,7 & 0,9 & 1,0 & $\mathrm{P}_{0}=0,363$ \\
\hline Number of failures* (cumulatively) & 0,0 & 0,0 & 0,2 & 0,4 & 0,5 & 0,8 & 0,9 & 0,9 & $\begin{array}{l}\text { Leading function } \\
\text { of flow of failures }\end{array}$ \\
\hline $\begin{array}{l}\text { Probability } \mathrm{P}_{\mathrm{i}} \text { in consideration of } \\
\text { redundancy }\end{array}$ & 1,0 & 1,0 & 0,94 & 0,8 & 0,98 & 0,7 & 0,97 & 1,0 & $\mathrm{P}_{0} *=0,500$ \\
\hline $\begin{array}{l}\text { Costs associated with performance } \\
\text { restoration*, thous. rub. }\end{array}$ & 0 & 0 & 0,15 & 1,3 & 2 & 0,7 & 0,1 & 0 & $\begin{array}{l}\text { Intensity of flow } \\
\text { of costs }\end{array}$ \\
\hline $\begin{array}{l}\text { Costs associated with performance } \\
\text { restoration * (cumulatively), thous. } \\
\text { rub. }\end{array}$ & 0 & 0 & 0,15 & 1,45 & 3,45 & 4,15 & 4,25 & 4,25 & $\begin{array}{l}\text { Leading function } \\
\text { of flow of costs }\end{array}$ \\
\hline
\end{tabular}

Thus the probability of faultless operation of corrected supply chain is $\mathrm{P}^{*}=0,500$.

Table 6. Calculation results of indicators of the supply chain reliability

Consider the economic approach to assessing the reliability of the supply chain. Current state of the considered supply chain can be evaluated on the basis of data collected by constructing "the flow of failures" in the form of the leading function of flow of costs, which allows characterizing the reliability 
of supply chains as restorable systems. The leading function is constructed (Figure 4) on the basis of data of costs calculated cumulatively (Table 6).

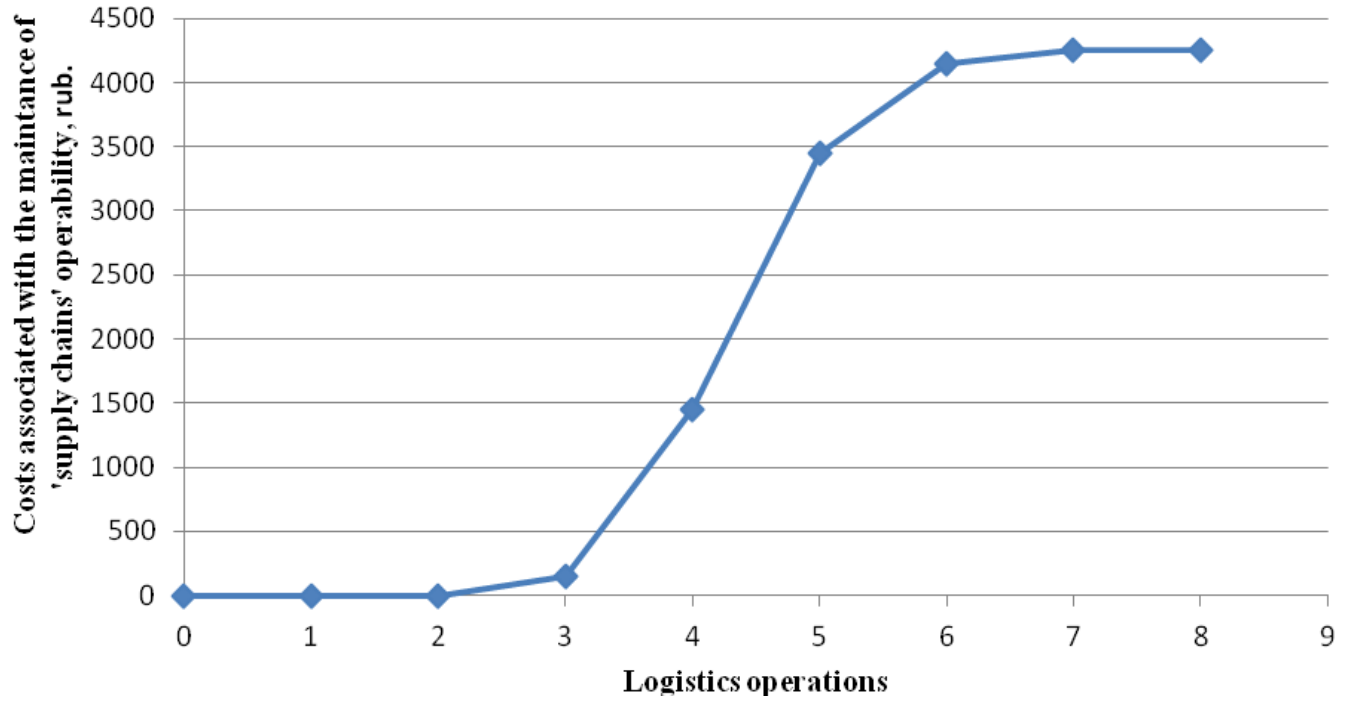

Figure 4. Leading function of flow of costs associated with the maintenance of supply chains' operability

\section{Conclusions}

The results of calculations of probabilities of supply chains' faultless operation, which take into account the elements of redundancy in the form of insurance stocks in the warehouses of suppliers and consumers, differ significantly from the results obtained on the basis of existing approach, which implies the sequential execution of logistics operations without corrections. It emphasizes once again that supply chain should be seen as a system of "man-machine-environment", which integrates the material and accompanying flows (financial, information flows and others) and is capable of self-organization and self-learning.

The proposed terminology of basic concepts and definitions of reliability of supply chains undoubtedly requires further discussion and improvement. At the same time, after the unifying of terminology it will be possible to form unambiguous and reliable databases of real supply chains.

Analysis of the intensities and leading functions of flows of costs associated with the maintenance of supply chains' operability makes it possible not only to evaluate their effectiveness, but also to find alternative solutions that will improve their reliability. Simultaneous use of probabilities of faultless operation of logistics operations and the flows of costs is the basis for the finding of "bottlenecks" in the supply chain and will promote making optimal management decisions for the elimination of these "bottlenecks" in case of limited resources.

Further development of the proposed approach for assessing the reliability of the supply chain, in our opinion, is impossible without the formation of new analytical tools in the form of complex models of failures while executing logistics operations, and these new analytical tools should be used not only for existing supply chains, but also during the design or re-engineering of logistics systems.

\section{References}

1. Ballou, R.N. (1999). Business logistics Management. New Jersey: Prentice-Hill International.

2. Bowersox, D.J., Closs, D.J. (1996). Logistical Management. The Integrated Supply Chain Process. New York: McGraw-Hill.

3. Blanchard, Benjamin S. (2004). Logistics Engineering and Management. $6^{\text {th }}$ ed. USA: Pearson. Prentice Hall.

4. Gertsbakh, B., Kordonsky, K. (1966). Models of failures. Soviet radio.

5. Christopher, M. (2004). Logistics and supply chain management. Harlow, UK: FT Prentice Hall.

6. Institute of Electrical and Electronics Engineers. (1990). IEEE standard Computer Dictionary: A Complication of IEEE Standard Computer Glossuries. New York. 
7. Lukinskiy, V.S., Lukinskiy, V.V., Malevich, J.V., Plastuniak, I.A., Pletneva, N.G. (2007). Models and methods of the logistics theory. St.Petersburg: Piter.

8. Lukinskiy, V., Churilov, R. (2013). Assessment of the Supply Chains Reliability. Logistics, 4 (77).

9. Wolfgang, K., Thorsten, B. (2006). Managing Risks in Supply Chains. How to Build Reliable Collaboration in Logistics. Berlin: Erich Schmidt Verlag.

10. Mirotin, L.B., Sergeev, V.I. (2002). Principles of Logistics. M.: INFRA-M.

11. Rao, S.S. (1992). Reliability - Based Design. McGraw-Hill.

12. Stock, J.R., Lambert, D.M. (2001). Strategic Logistics Management. $4^{\text {th }}$ Ed. New York: McGraw Hill Irwin.

13. Zaitzev, E.I., Bochazev, A.A. (2010). Optimizing supply-planning in multi-level network structures in the light of reliability. Logistics and Supply Chain Management, 2 (37).

14. Zaitzev, E.I., Uvarov, S.A. (2012). Using indicators of Perfect Order Fulfillment in the distribution logistics. Logistics and Supply Chain Management, 4(51). 